EGU2020-8401

https://doi.org/10.5194/egusphere-egu2020-8401

EGU General Assembly 2020

(c) Author(s) 2020. This work is distributed under

the Creative Commons Attribution 4.0 License.

\title{
Comparing the discrimination power of contrasted sediment tracing techniques to quantify the impact of nickel mining on river and lagoon siltation in New Caledonia
}

\author{
Virginie Sellier ${ }^{1}$, Olivier Evrard ${ }^{1}$, Oldrich Navratil ${ }^{2}$, J. Patrick Laceby ${ }^{3}$, Michel Allenbach $^{4}$, and Irène \\ Lefèvre ${ }^{1}$ \\ ${ }^{1}$ CNRS, LSCE, Gif-sur-Yvette Cedex, France (virginie.sellier@Isce.ipsl.fr) \\ ${ }^{2}$ Laboratoire Environnement-Ville-Société (UMR 5600), Université Lumière Lyon 2, Lyon, France, \\ ${ }^{3}$ Environmental Monitoring and Science Division (EMSD), Alberta, Canada \\ ${ }^{4}$ Université de la Nouvelle-Calédonie, Nouméa, Nouvellle-Calédonie
}

Open-cast mining has strongly increased soil erosion and the subsequent downstream transfer of sediments in river systems. New Caledonia, a French island located in the south-west Pacific Ocean and currently the world's 6th largest nickel producer, is confronted in particular to unprecedented sediment pollution of river systems: hyper-sedimentation. A significant fraction of this sediment is likely originating from tributaries draining nickel mining sites. Nevertheless, the contribution of this sediment source has not been quantified and this estimation is required to guide the implementation of efficient management measurements to mitigate fine sediment supply to New Caledonian river systems and lagoons. To this end, a pilot sediment tracing study has been conducted in one of the first areas exploited for nickel mining, the $397-\mathrm{km}^{2}$ Thio River catchment.

Sediment deposits were collected after two major floods ( 10 yr return period): the tropical depression of February 25, 2015 and Cyclone Cook on April 10, 2017. Sources $(n=25)$ were sampled on (i) tributaries draining mines, and (ii) tributaries draining 'natural' areas affected by landslides occurring frequently in the region, and sediment $(n=19)$ on (iii) the main stem of the Thio River. In addition, (iv) a $1.60 \mathrm{~m}$ long sediment core was collected in the Thio river deltaic floodplain in April 2016. Six sediment tracing techniques were tested based on the following properties: fallout radionuclides, geogenic radionuclides, elemental geochemistry, colorimetric parameters and reflectance spectra.

Several of these methods were identified as relevant to the New Caledonian context and allowed to estimate the contributions of both mining and non-mining sources according to their variations both in space and time. In particular, the sedimentary contributions of mining sources were estimated between $65-68 \%$ for the 2015 flood and 83-88 \% for the 2017 flood. The impact of the spatial variability of precipitation was highlighted to explain the variations in the spatial contributions of the sources. The temporal variations in the contributions of the sources deduced from the analysis of the sediment core were interpreted at the light of the mining history in the Thio River catchment (pre-mechanization, mechanization, post-mechanization of mining activity). 
The contributions of mining sources were again dominant with an average contribution along the sedimentary profile of $74 \pm 13 \%$.

In the future, similar studies should be carried out in other catchments draining mines in New Caledonia and potentially across similar South Pacific and other tropical islands. 